\title{
An Observational Study on the Clinical and Nutritional Factors Determining the Kidney Function at One Year after Transplantation
}

\author{
Nao Kawabata1,2*, Toshiko Sato1, Koji Nanmoku³, Daisuke Nagata4, Shizukiyo Ishikawa5, \\ Shun Ishibashi ${ }^{1,6}$, Takashi Yagisawa3 ${ }^{3}$, Yoshio Uehara² \\ ${ }^{1}$ Department of Clinical Nutrition Jichi Medical University Hospital, Shimotsuke, Tochigi, Japan \\ ${ }^{2}$ Graduate School of Home Economics Kyoritsu Women's University, Tokyo, Japan \\ ${ }^{3}$ Division of Renal Surgery and Transplantation, Department of Urology, Jichi Medical University, Shimotsuke, Tochigi, Japan \\ ${ }^{4}$ Division of Nephrology, Department of Internal Medicine, Jichi Medical University, Shimotsuke, Tochigi, Japan \\ ${ }^{5}$ Medical Education Center, Jichi Medical University, Shimotsuke, Tochigi, Japan \\ ${ }^{6}$ Division of Endocrinology and Metabolism, Department of Internal Medicine, Jichi Medical University, Shimotsuke, Tochigi, \\ Japan \\ Email: ^nkawabata@jichi.ac.jp
}

How to cite this paper: Kawabata, N., Sato, T., Nanmoku, K., Nagata, D., Ishikawa, S., Ishibashi, S., Yagisawa, T. and Uehara, Y. (2018) An Observational Study on the Clinical and Nutritional Factors Determining the Kidney Function at One Year after Transplantation. Food and Nutrition Sciences, 9, 1299-1315. https://doi.org/10.4236/fns.2018.911093

Received: October 8, 2018

Accepted: November 19, 2018

Published: November 22, 2018

Copyright (C) 2018 by authors and Scientific Research Publishing Inc. This work is licensed under the Creative Commons Attribution International License (CC BY 4.0).

http://creativecommons.org/licenses/by/4.0/

\section{(c) (7) Open Access}

\begin{abstract}
Objective: The aim of the present study was to investigate the clinical and nutritional factors influencing the renal function of the transplanted kidney during a one-year follow-up period after transplantation. Patients: The present prospective observational study included 52 patients who underwent kidney transplantation at Jichi Medical University Hospital from 2014 to 2016. Results: The serum creatinine $(\mathrm{sCr})$ concentration at one month after transplantation was closely related to the concentration at 12 months. The recipients were divided into two groups based on the $\mathrm{sCr}$ concentration at one month after transplantation. Recipients with a sCr concentration greater than or equal to the median were classified into Group $\mathrm{H}$, while those with concentrations that were less than the median were classified into Group L. A stepwise multiple regression analysis demonstrated that the salt intake in male recipients was an independent predictor of the renal function at 12 months $(\beta=0.663, \mathrm{p}<0.01)$, while the BMI was an independent factor in female recipients $(\beta=0.618, \mathrm{p}<0.01)$. Moreover, in female recipients, the BMI and serum uric acid values in Group $\mathrm{H}$ were significantly higher than those in Group L. The BMI values of the female recipients in Group H were significantly higher than those in Group L at all times during the follow-up period $(\mathrm{p}<0.01)$. Conclusion: The daily salt intake was independently associated with the renal function at one year after kidney transplantation in male recipients. In female recipients, the BMI was independently associated with the sCr concentration during the one-year follow-up period.
\end{abstract}




\section{Keywords}

Salt, Obesity, Uric Acid, Serum Creatinine, Kidney Function

\section{Introduction}

Patients with end-stage kidney disease (ESKD) are usually treated with hemodialysis, peritoneal dialysis or kidney transplantation. Kidney transplantation is superior to the other treatments as it benefits the quality of life and improves the prognosis with regard to cardiovascular complications. In Japan, the number of kidney transplants has been increasing since cyclosporine, a potent immunosuppressant, was introduced in the clinical setting. In 2015, 1,661 patients received kidney transplants in Japan, and the number of living and deceased donor reached 1494 and 167, respectively [1].

Kidney transplant recipients are usually managed with special care during the follow-up period (i.e., the early post-operative phase of $1-2$ weeks, the early post-transplant follow-up phase of 3 - 4 months, and the long-term follow-up phase). During the long-term follow-up phase, the risk of infection or acute rejection decreases with the stability of the renal function because the self-defense system is rebuilt in the recipient.

The renal function after transplantation is influenced by the presence of one kidney, chronic rejection or the recurrence of nephritis. The glomerular filtration rate (GFR) of the transplanted kidney is maintained at $50-70 \mathrm{~mL} / \mathrm{min} / 1.73$ $\mathrm{m}^{2}$, and this causes glomerular hyperfiltration in the residual nephrons [2]. Moreover, kidney transplant recipients experience an increased appetite due to corticosteroid treatment, particularly during the first year. Weight gain, metabolic syndrome and hypertension often reduce graft survival [3] [4] [5] [6] [7]. Since the serum creatinine concentration at one year after transplantation is a predictor of graft survival [8], it is important to improve the kidney prognosis, and the guidelines, including the guidelines of the Expert Working Group Report on Nutrition in Adult Patients with Renal Insufficiency [9] and Dietitians Association of Australia (DAA) and Caring for Australasian with Renal Impairment (CARI) [10] state the importance of controlling nutritional behavior. In Japan, however, evidence is very limited, and is only described in the Clinical Guideline for Medical and Pediatric Complications after Kidney Transplantation 2011 [11] and Dietary Recommendations for Chronic Kidney Disease 2014 [12]. The optimum nutritional strategy for post-transplant patients remains to be elucidated.

Thus, in the present study, we investigated the clinical and nutritional factors influencing the renal function after kidney transplantation using the one-year follow-up data of patients who underwent kidney transplantation in Jichi Medical University Hospital. 


\section{Subjects and Methods}

\subsection{Ethical Considerations}

The study protocol was approved by the ethics committee of the Jichi Medical University (No.15-067). The authors declare no conflicts of interest in association with the present study. Informed consent was obtained in the form of opt-out on the web-site and those who rejected were excluded.

\subsection{Subjects}

Fifty-four recipients who were over 20 years of age were enrolled in this study. The recipients were managed in Jichi Medical University Hospital from 2014 to 2016. Two recipients dropped out because their body weight and 24-h urine collection data were not available. Fifty-two recipients (male, $\mathrm{n}=32$; female, $\mathrm{n}=$ 20) completed the study.

\subsection{Design of Study}

This study was based on the interim analysis during 12 months of 5 year-prospective observational study. We examined the baseline characteristics of kidney donors and recipients. The donor factors that were collected included gender, age and the glomerular filtration rate (GFR). The GFR was assessed as the creatinine clearance rate using 24-h urine. The recipient factors that were collected included age, causative disease, dialysis history, operative time, hemorrhage volume during operation, serum $\mathrm{Cr}$ concentration, body mass index (BMI), primary disease and medication details.

The study protocol is shown in Figure 1. The clinical and laboratory data (BMI, systolic blood pressure, diastolic blood pressure, serum $\mathrm{Cr}, \mathrm{HbA1c}$, albumin, uric acid, potassium, phosphorus, triglyceride, high density lipoprotein cholesterol and low density lipoprotein cholesterol concentrations) were determined at 1, 3, 6 and 12 months after transplantation. Low density lipoprotein cholesterol was calculated by Friedwald formula. Furthermore, the dietary protein and salt intake were measured at 3, 6 and 12 months after transplantation. The dietary protein [13] and salt intake of each recipient was determined from 24-h urine collection. According to the Guidelines for the Management of Hypertension 2014 (Japanese Society of Hypertension), casual blood pressures were measured using an automated blood pressure monitoring system (Omron, BP-203RVIII, Kyoto, Japan). The measurements were performed two or more times at intervals of $1-2 \mathrm{~min}$, and the mean value of the two measurements was used [14]. A blood analysis was performed using an auto analyzer (Hitachi High-Technologies Corp. LABOSPECT $008 \alpha$, Tokyo, Japan).

\subsection{Statistical Analysis}

The data were analyzed using an independent $t$-test, Mann-Whitney test, chi-squared test, Fisher's exact test, the Friedman test, a repeated measures analysis of variance, a two-way repeated measures analysis of variance, or mixed-effects 


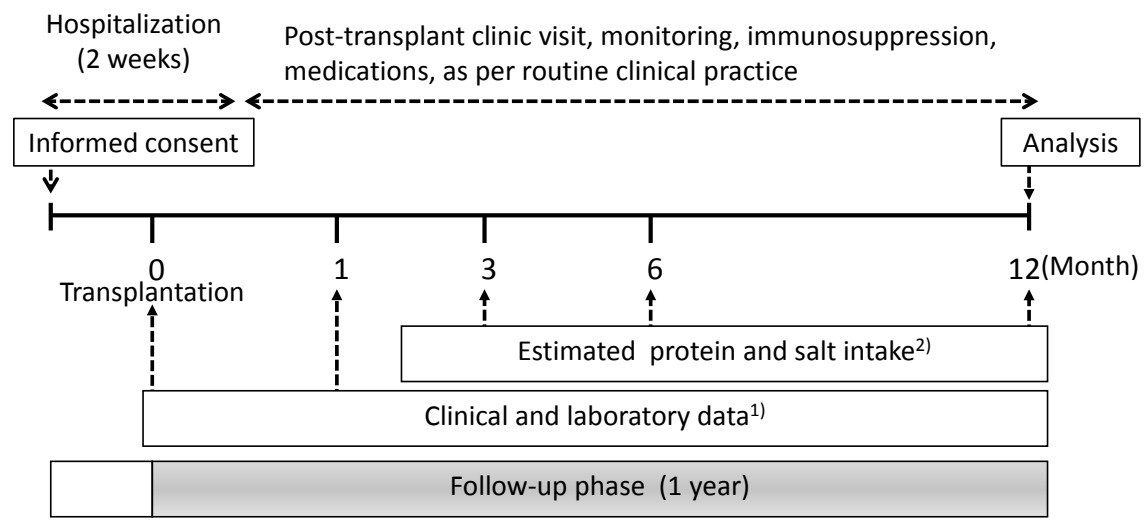

1) $\mathrm{BMI}$, systolic blood pressure, diastolic blood pressure, serum $\mathrm{Cr}, \mathrm{HbA1c}$, albumin, uric acid, potassium, phosphorus, triglyceride, high density lipoprotein cholesterol and low density lipoprotein cholesterol

2) The dietary protein and salt intake was determined using from a 24-hour urine collection.

Figure 1. The study protocol.

mode. Bivariate correlations were analyzed using Pearson's product moment correlation coefficient or Spearman's rank correlation coefficient, and a stepwise multiple regression analysis was performed to identify independent factors. $P$ values of $<0.05$ were considered to indicate statistical significance. The statistical analyses were performed using the SPSS ${ }^{\circledast}$ Statistics 21 software program (IBM, Armonk, NY, USA).

\section{Results}

\subsection{The Renal Function after Kidney Transplantation}

The changes in the serum $\mathrm{Cr}$ concentrations of the recipients in the year after transplantation are shown in Figure 2. The serum $\mathrm{Cr}$ concentrations of both male and female recipients were decreased at 1-month, and then remained almost constant for 12 months. Moreover, the serum $\mathrm{Cr}$ concentrations at 12 months were significantly correlated with those at 1 month (Figure 3 ).

The distributions of the serum $\mathrm{Cr}$ concentrations at 12 months are shown in Figure 4. The concentrations ranged widely, from almost normal to relatively higher concentrations. Thus, we divided the recipients into two groups and analyzed the factors influencing the kidney function at 12 months after transplantation. Recipients whose serum $\mathrm{Cr}$ concentrations were greater than or equal to the median (male; $1.28 \mathrm{mg} / \mathrm{dL}$, female; $0.88 \mathrm{mg} / \mathrm{dL}$ ) were classified into Group $\mathrm{H}$, while those whose values were less than the median were classified into Group L. Furthermore, we stratified the data by gender (Figure 5).

In male recipients, the serum $\mathrm{Cr}$ concentrations of Group $\mathrm{H}$ were significantly higher than those of Group L during the one-year follow-up period $(p<0.01)$, and the concentrations remained stable from 1 month to 12 months $(p=0.633$ and $p=0.907$, respectively). Similarly, in female recipients, the serum $\mathrm{Cr}$ concentrations in Group H were significantly higher than those in Group L 

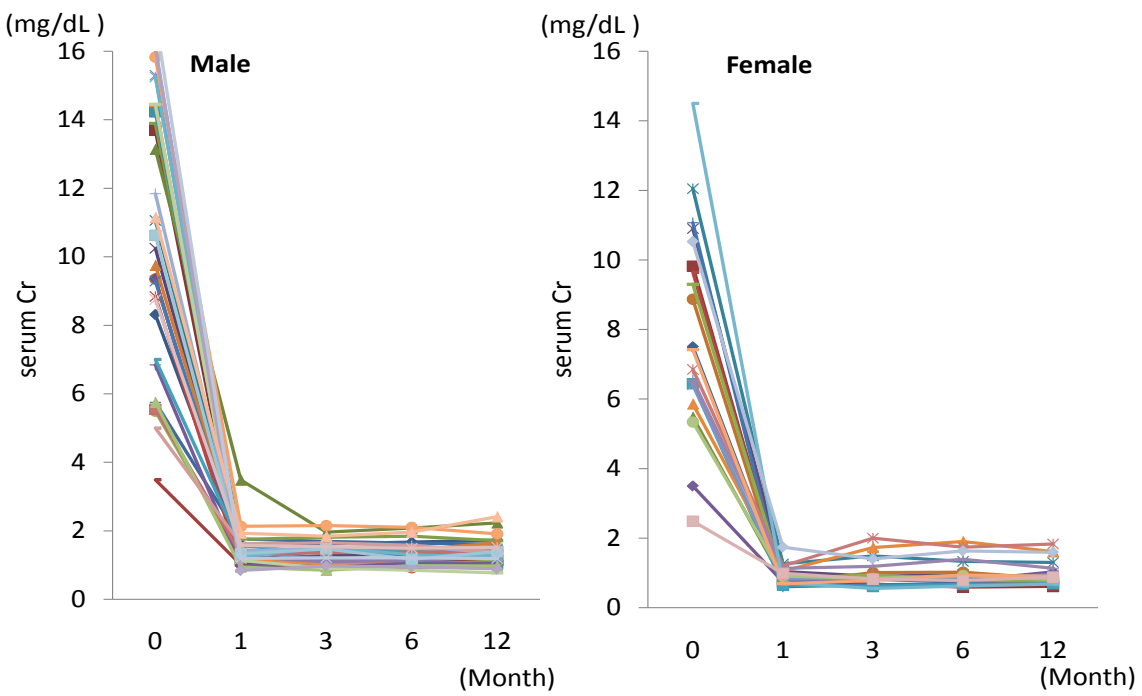

Figure 2. The clinical course of the serum Cr concentrations during the one year follow-up period. The left graph shows the $\mathrm{Cr}$ concentrations in male recipients. The right graph shows the $\mathrm{Cr}$ concentrations in female recipients.
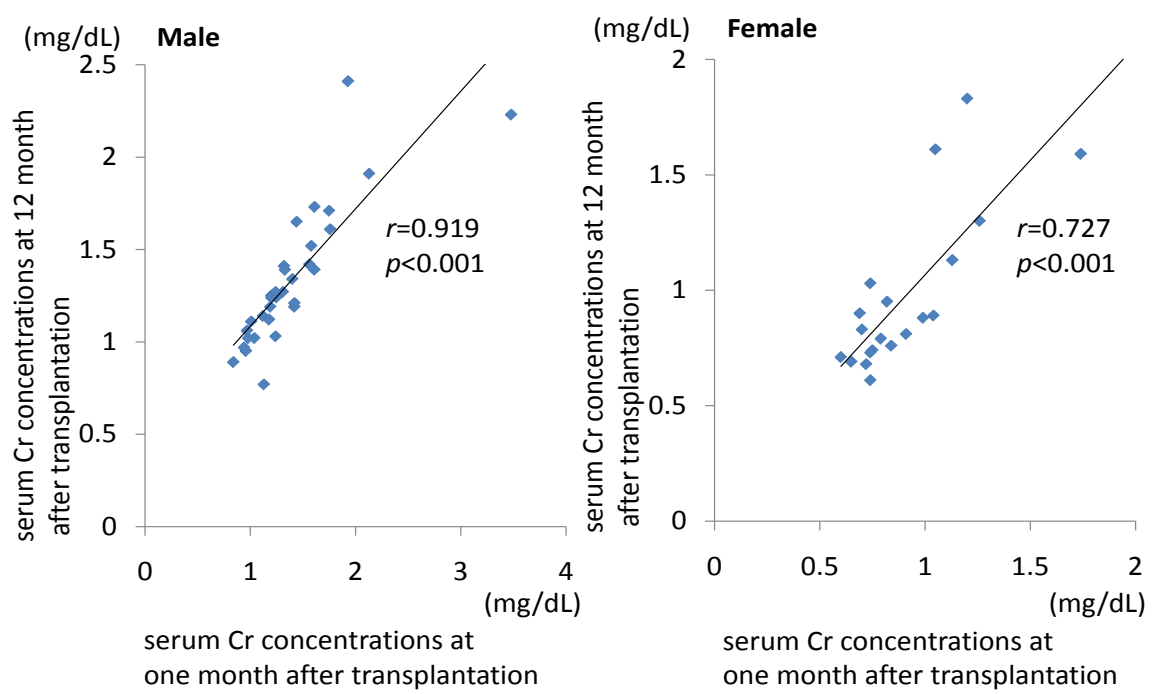

Figure 3. Correlation between the serum Cr concentrations at one month and 12 months after transplantation. The left graph shows the correlation in male recipients. The right graph shows the correlation in female recipients. The data were analyzed using Pearson's product-moment correlation.

during the one-year follow-up period $(p<0.01)$, and the serum $\mathrm{Cr}$ concentrations remained stable from 1 month to 12 months $(p=0.353$ and $p=0.411$, respectively). Based on these results, we analyzed the factors influencing the serum $\mathrm{Cr}$ concentrations at 12 months after transplantation in Groups $\mathrm{H}$ and L.

\subsection{The Background Characteristics of the Donors and Recipients}

The background characteristics of the donors and recipients at the time of transplantation are shown in Table 1. Among the donors, there were no differences in gender, age, or GFR between Groups $\mathrm{H}$ and L. 


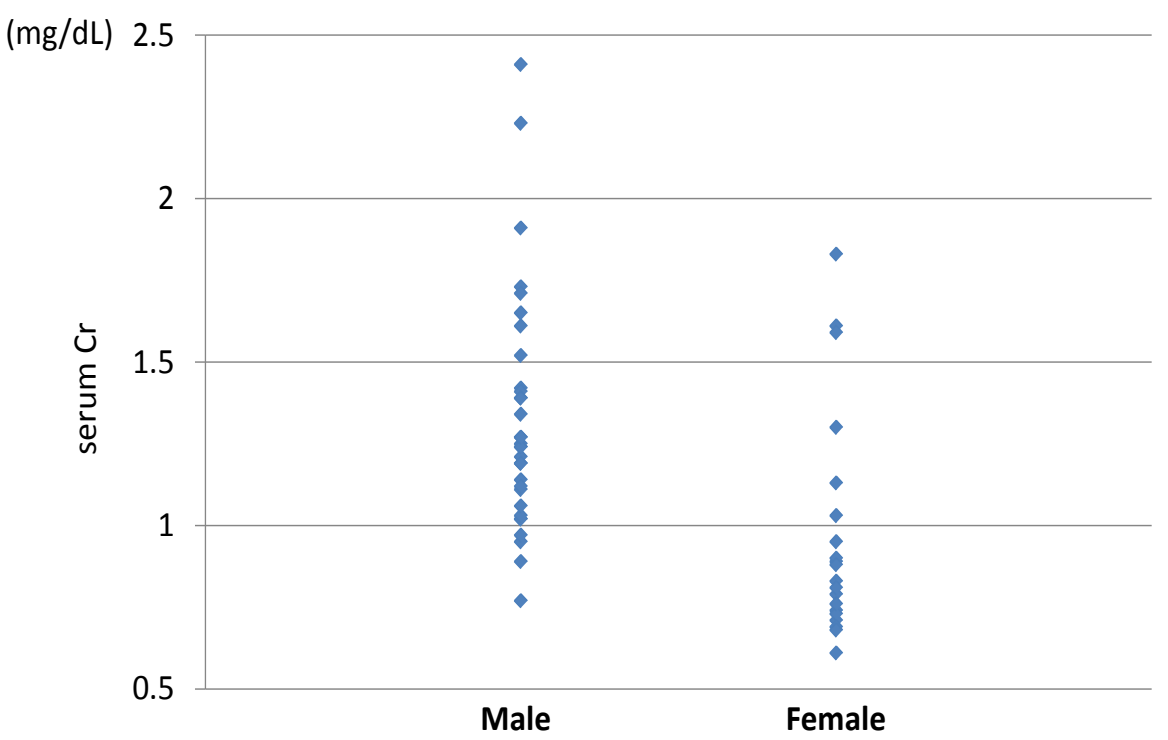

Figure 4. The distribution of the serum $\mathrm{Cr}$ concentrations at 12 months. The left graph shows the serum $\mathrm{Cr}$ concentrations in male recipients. The right shows the serum $\mathrm{Cr}$ concentrations in female recipients.

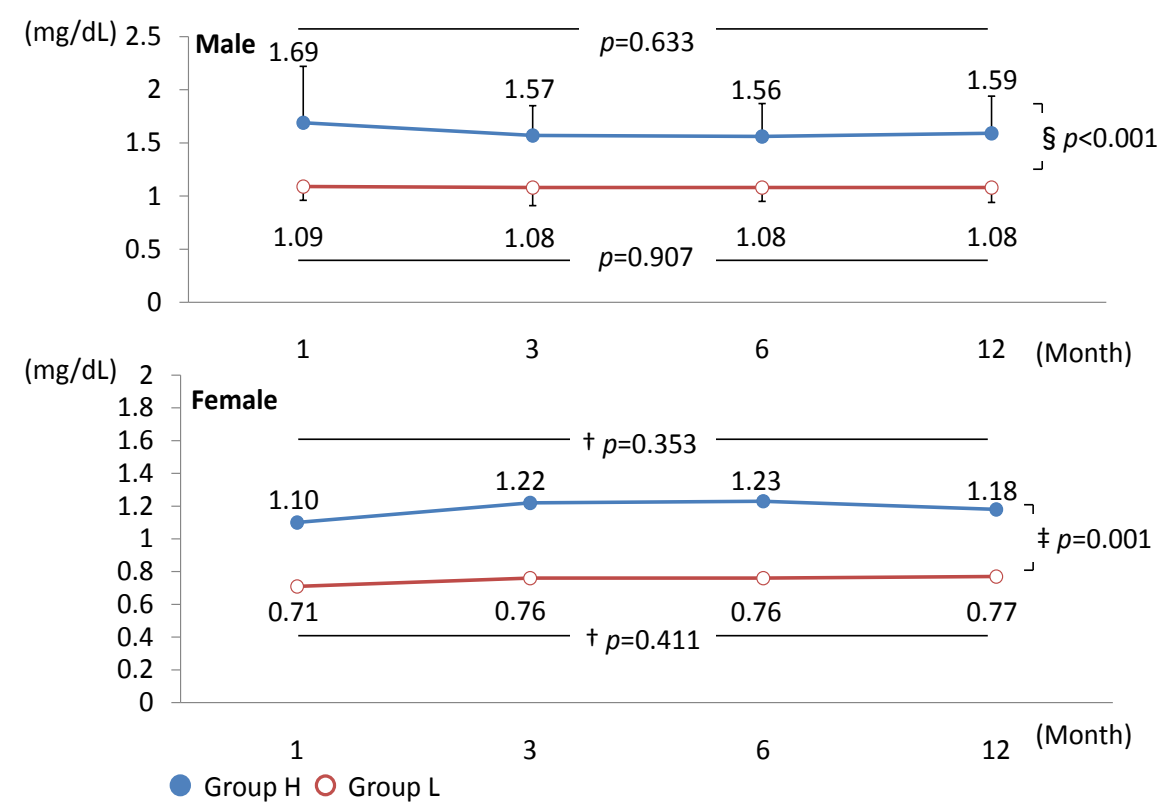

Figure 5. The clinical course of the serum $\mathrm{Cr}$ concentrations during the study period. The values are expressed as mean \pm SD. The open circles represent the values in Group L. The closed circles represent the values in Group $\mathrm{H}$. The vertical axis represents the serum $\mathrm{Cr}$ concentrations, while the horizontal axis represents the period of the study. The upper graph shows male recipients, while the lower graph shows female recipients. The differences in each group of male recipients during the whole study period were analyzed by the Friedman test ( $p=0.633$ for Group H and $p=0.907$ for Group L). The differences in each group of female recipients during the whole study period were analyzed by a repeated measures ANOVA $(\dagger)(p=0.353$ for Group H and $p=0.411$ for Group L). The differences between Groups $\mathrm{L}$ and $\mathrm{H}$ during the whole study period were analyzed by a mixed-effects model $(\S)$ or a two-way repeated measures ANOVA $(\ddagger)(p<0.001$ for male recipients and $p<0.01$ for female recipients). 
Table 1. Characteristics of the recipients and the donors at the time transplantation.

\begin{tabular}{|c|c|c|c|c|c|c|c|c|}
\hline & Male & Female & & & & & & \\
\hline & $\begin{array}{c}\text { Total } \\
(\mathrm{n}=32)\end{array}$ & $\begin{array}{l}\text { Group H } \\
(\mathrm{n}=16)\end{array}$ & $\begin{array}{l}\text { Group L } \\
(\mathrm{n}=16)\end{array}$ & $\begin{array}{l}p \text { value } \\
(\mathrm{H} \text { vs } \mathrm{L})\end{array}$ & $\begin{array}{c}\text { Total } \\
(\mathrm{n}=20)\end{array}$ & $\begin{array}{l}\text { Group H } \\
(\mathrm{n}=10)\end{array}$ & $\begin{array}{l}\text { Group L } \\
(\mathrm{n}=10)\end{array}$ & $\begin{array}{l}p \text { value } \\
(\mathrm{H} \text { vs L) }\end{array}$ \\
\hline \multicolumn{9}{|l|}{$\underline{\text { Donor factors }}$} \\
\hline Sex (Male/Female) (N) & $12 / 20$ & $5 / 11$ & $7 / 9$ & 0.465 & $14 / 6$ & $6 / 4$ & $8 / 2$ & 0.628 \\
\hline Age (years) & $57.0 \pm 10.8$ & $58.0 \pm 10.5$ & $56.1 \pm 11.3$ & 0.569 & $58.1 \pm 7.5$ & $58.0 \pm 8.4$ & $58.1 \pm 7.0$ & 0.977 \\
\hline $\mathrm{eGFR}\left(\mathrm{mL} / \mathrm{min} / 1.73 \mathrm{~m}^{2}\right)$ & $103[88-123]$ & $106 \pm 23$ & $111 \pm 22$ & 0.948 & $120 \pm 18$ & $119 \pm 17$ & $122 \pm 19$ & 0.743 \\
\hline \multicolumn{9}{|l|}{$\underline{\text { Recipient factors }}$} \\
\hline Age (years) & $46.3 \pm 14.2$ & $43.8 \pm 13.1$ & $48.8 \pm 15.1$ & 0.516 & $47.9 \pm 14.6$ & $48.6 \pm 16.8$ & $47.2 \pm 12.9$ & 0.837 \\
\hline Dialysis history (months) & $20[14-41]$ & $21[14-38]$ & $20[14-49]$ & 0.827 & $21[10-53]$ & $36 \pm 17$ & $13[7-71]$ & 0.205 \\
\hline Operative time (hours) & $4.2[3.3-4.5]$ & $4.1[3.3-4.8]$ & $4.2[3.7-4.5]$ & 0.706 & $4.0[3.5-4.8]$ & $4.4[3.5-5.0]$ & $3.8[3.5-4.1]$ & 0.256 \\
\hline Hemorrhage volume $(\mathrm{mL})$ & $179 \pm 127$ & $211 \pm 147$ & $146 \pm 96$ & 0.120 & $180[111-353]$ & $240[150-403]$ & $167 \pm 141$ & 0.069 \\
\hline $\begin{array}{l}\text { Serum Cr concentrations } \\
\qquad(\mathrm{mg} / \mathrm{dL})\end{array}$ & $10.71 \pm 3.88$ & $10.19 \pm 3.44$ & $11.24 \pm 4.33$ & 0.119 & $8.03 \pm 2.98$ & $7.63 \pm 2.97$ & $8.43 \pm 3.10$ & 0.564 \\
\hline BMI $\left(\mathrm{kg} / \mathrm{m}^{2}\right)$ & $24.3 \pm 4.2$ & $25.3 \pm 4.6$ & $23.3 \pm 3.6$ & 0.708 & $\begin{array}{c}22.4[17.5- \\
26.3]\end{array}$ & $25.6 \pm 4.4$ & $\begin{array}{c}17.8[17.3- \\
23.5]\end{array}$ & 0.004 \\
\hline \multicolumn{9}{|l|}{ Primary disease $(\mathrm{N})$} \\
\hline Chronic nephritic syndrome & $16(50)$ & $9(56)$ & $7(44)$ & 0.723 & $12(60)$ & $5(50)$ & $7(70)$ & 0.325 \\
\hline IgA nephropathy & $4(13)$ & $3(19)$ & $1(6)$ & 0.285 & $3(15)$ & $1(5)$ & $2(20)$ & 0.500 \\
\hline $\begin{array}{l}\text { Mesangial proliferative } \\
\text { glomerulonephritis }\end{array}$ & $1(3)$ & $0(0)$ & $1(6)$ & 0.500 & $0(0)$ & $0(0)$ & $0(0)$ & - \\
\hline Nephrosclerosis & $0(0)$ & $0(0)$ & $0(0)$ & - & $2(10)$ & $2(20)$ & $0(0)$ & 0.237 \\
\hline Focal glomerulonephritis & $2(6)$ & $1(6)$ & $1(6)$ & 0.758 & $0(0)$ & $0(0)$ & $0(0)$ & - \\
\hline Lupus nephritis & $0(0)$ & $0(0)$ & $0(0)$ & - & $1(5)$ & $0(0)$ & $1(5)$ & 0.500 \\
\hline Not clear & $9(28)$ & $5(31)$ & $4(25)$ & 0.500 & $6(30)$ & $2(20)$ & $4(40)$ & 0.314 \\
\hline Diabetic nephropathy & $10(31)$ & $6(38)$ & $4(25)$ & 0.446 & $4(20)$ & $3(30)$ & $1(10)$ & 0.291 \\
\hline $\begin{array}{l}\text { ANCA-associated } \\
\text { glomerulonephritis }\end{array}$ & $0(0)$ & $0(0)$ & $0(0)$ & - & $2(10)$ & $2(20)$ & $0(0)$ & 0.237 \\
\hline $\begin{array}{l}\text { Autosomal dominant } \\
\text { polycystic kidney disease }\end{array}$ & $3(9)$ & $0(0)$ & $3(19)$ & 0.242 & $1(5)$ & $0(0)$ & $1(10)$ & 0.500 \\
\hline APRT deficiency & $1(3)$ & $1(6)$ & $0(0)$ & 0.500 & $0(0)$ & $0(0)$ & $0(0)$ & - \\
\hline Alport syndrome & $1(3)$ & $0(0)$ & $1(6)$ & 0.500 & $0(0)$ & $0(0)$ & $0(0)$ & - \\
\hline Behcet's disease & $0(0)$ & $0(0)$ & $0(0)$ & - & $1(5)$ & $0(0)$ & $1(10)$ & 0.500 \\
\hline Drug-induced nephropathy & $1(3)$ & $0(0)$ & $1(6)$ & 0.500 & $0(0)$ & $0(0)$ & $0(0)$ & - \\
\hline
\end{tabular}

Values are expressed as the mean \pm standard deviation, median [interquartile range] or the number of recipients (percentage). Independent $t$-test、 Mann-Whitney test Fisher's exact test.

Among the male recipients, the average age of the male recipients was $46.3 \pm$ 14.2 years ( $26-71$ years, median 44.5 years), and the average period of dialysis was 20 months (0 - 193 months). Twenty recipients were on hemodialysis, 6 were on peritoneal dialysis and 6 received preemptive kidney transplantation. Among the female recipients, the average age was $47.9 \pm 14.6$ years $(23-72$ years, median 49.5 years), and the average dialysis period was 21 months (0 - 128 
months). Seventeen recipients were on hemodialysis, 2 were on peritoneal dialysis and 1 received preemptive kidney transplantation. The major causative diseases were chronic nephritic syndrome due to diabetes in both male and female recipients. There were no differences in the BMI values of the male recipients in Groups $\mathrm{H}$ and L, whereas the BMI values of female recipients in Group $\mathrm{H}$ were significantly greater than those in Group L.

\subsection{The Cross-Sectional Analysis of Factors Influencing the Serum Cr Concentrations at 12 Months after Transplantation}

Using the overall data, we analyzed the clinical and nutritional factors that were correlated with the renal function at 12 months after transplantation (Table 2). The serum $\mathrm{Cr}$ concentrations were positively correlated with the daily intake of protein and salt in the male recipients, while the serum uric acid concentrations and BMI were positively correlated in the female recipients. In the stratified analysis, it was demonstrated that the intake of protein and salt was positively correlated with the $\mathrm{Cr}$ concentrations at 12 months in male recipients in Group $\mathrm{H}$, while the correlations disappeared in male recipients in Group L. On the other hand, in female recipients, the uric acid concentrations or BMI was not significantly associated with the renal function at 12 months after transplantation both in Group H and Group L. Based on the results from the bivariate correlation analysis, we attempted to isolate independent determinants of the serum $\mathrm{Cr}$ concentrations at 12 months after transplantation using a stepwise multiple regression analysis (Table 3 ). In male recipients, the salt intake was found to be an independent predictor of the renal function at 12 months $(\beta=0.663, p<0.01)$. On the other hand, in female recipients, the BMI was independently associated with the renal function at 12 months after transplantation $(\beta=0.618, p<0.01)$.

Table 2. The cross-sectional analysis of factors associated with the serum Cr levels at 12 months after transplantation.

\begin{tabular}{|c|c|c|c|c|c|c|}
\hline & \multicolumn{3}{|c|}{ Male } & \multicolumn{3}{|c|}{ Female } \\
\hline & Total $(\mathrm{n}=32)$ & Group H ( $\mathrm{n}=16)$ & Group L $(\mathrm{n}=16)$ & Total $(\mathrm{n}=20)$ & Group H $(\mathrm{n}=10)$ & Group L $(n=10)$ \\
\hline SBP & 0.284 & 0.019 & 0.184 & 0.166 & 0.036 & -0.574 \\
\hline DBP & -0.010 & -0.242 & -0.115 & -0.354 & 0.244 & -0.302 \\
\hline HbAlc & -0.237 & 0.160 & -0.282 & 0.234 & 0.260 & 0.329 \\
\hline Serum Alb levels & 0.138 & 0.313 & $0.552^{*}$ & -0.013 & -0.477 & 0.318 \\
\hline Serum uric acid levels & 0.282 & 0.183 & $0.552^{*}$ & $0.668^{* *}$ & 0.362 & 0.395 \\
\hline Triglyceride & 0.172 & 0.472 & 0.252 & 0.354 & $0.700^{*}$ & -0.176 \\
\hline HDL cholesterol & 0.204 & -0.016 & 0.047 & -0.142 & -0.330 & 0.407 \\
\hline LDL cholesterol & 0.091 & 0.272 & -0.020 & 0.118 & 0.173 & -0.335 \\
\hline BMI & 0.283 & 0.256 & 0.069 & $0.514^{* *}$ & 0.468 & -0.036 \\
\hline Protein intake & $0.373^{*}$ & $0.518^{*}$ & -0.274 & 0.198 & -0.201 & -0.036 \\
\hline Salt intake & $0.412^{*}$ & $0.518^{*}$ & -0.088 & 0.147 & 0.244 & -0.424 \\
\hline
\end{tabular}

Values are expressed as the correlation coefficient. ${ }^{\star} p<0.05{ }^{* *} p<0.01$. Pearson's product moment correlation coefficient, Spearman's rank correlation coefficient. 
Table 3. Results from a stepwise multiple regression analysis to determine the factors independently associated with the serum Cr levels at 12 months after transplantation.

\begin{tabular}{|c|c|}
\hline \multirow{2}{*}{ Explanatory variable } & Dependent variable \\
\hline & $\begin{array}{l}\text { Serum Cr levels at } 12 \text {-month time point } \\
\text { after transplantation }\end{array}$ \\
\hline \multicolumn{2}{|l|}{$\underline{\text { Male }}$} \\
\hline Protein intake & - \\
\hline Salt intake & $0.663^{\star}$ \\
\hline Coefficient of determination & 0.440 \\
\hline \multicolumn{2}{|l|}{$\underline{\text { Female }}$} \\
\hline Serum uric acid levels & - \\
\hline BMI & $0.618^{\star}$ \\
\hline Coefficient of determination & 0.382 \\
\hline
\end{tabular}

Stepwise multiple regression analysis ${ }^{*} p<0.01$. Horizontal lines indicate the factors that were not selected as significant dependent variables by the Stepwise multiple regression analysis.

\subsection{The Management of Recipients and the Serum $\mathrm{Cr}$ Concentrations at 12 Months}

We analyzed the relationship between the clinical and nutritional management and the serum $\mathrm{Cr}$ concentrations at 12 months in Groups $\mathrm{L}$ and $\mathrm{H}$. The physical findings, laboratory data and medications at 1 month after transplantation are shown in Table 4 and Table 5. In the male recipients, there were no significant differences in any of these factors. In contrast, in female recipients, the BMI and serum uric acid concentrations in Group $\mathrm{H}$ were significantly higher than those in Group L.

Second, we demonstrated the clinical course of these parameters during the study period. In male recipients, the BMI values of the patients in Groups $\mathrm{L}$ and Group $\mathrm{H}$ did not differ to a significant extent. In contrast, in the female recipients, the BMI values of group $\mathrm{H}$ significantly higher than those of Group L ( $p$ $<0.01$ ) (Figure 6).

The SBP values of the two groups of male recipients did not differ to a significant extent, whereas in the female recipients, the SBP values of Group $\mathrm{H}$ were significantly higher than those of Group L $(p<0.05)$ (Figure 7). At 12 months after transplantation, in the female recipients, the SBP values of Group $\mathrm{H}$ were significantly higher than those of Group L $(p<0.05)$ (Figure 7).

The serum phosphorus concentrations of the two groups of male recipients did not differ to a significant extent. In contrast, the concentrations of the female recipients in Group H tended to be lower than those in Group L; however, the difference was not statistically significant (Figure 8).

The nutritional intake of the male recipients in Groups $\mathrm{L}$ and $\mathrm{H}$ did not differ to a statistically significant extent at any point in the study period. However, the female recipients in Group H consumed more salt than those in Group L ( $p<$ 0.05 ) (Figure 9). There were no differences in the other parameters at any point in the study period. 
Table 4. The physical findings, renal function and laboratory data at 1 month after transplantation in male patients.

\begin{tabular}{|c|c|c|c|c|}
\hline & $\begin{array}{c}\text { Total } \\
(\mathrm{n}=32)\end{array}$ & $\begin{array}{c}\text { Group H } \\
(\mathrm{n}=16)\end{array}$ & $\begin{array}{l}\text { Group L } \\
(\mathrm{n}=16)\end{array}$ & $p$ value ( $\mathrm{H}$ vs $\mathrm{L}$ ) \\
\hline \multicolumn{5}{|l|}{ Physical findings } \\
\hline SBP (mmHg) & $137 \pm 11$ & $137 \pm 12$ & $136 \pm 11$ & 0.712 \\
\hline $\mathrm{DBP}(\mathrm{mmHg})$ & $87 \pm 9$ & $86 \pm 10$ & $87 \pm 9$ & 0.728 \\
\hline BMI $\left(\mathrm{kg} / \mathrm{m}^{2}\right)$ & $22.7[20.0-24.7]$ & $24.2 \pm 4.6$ & $21.9 \pm 3.2$ & 0.110 \\
\hline \multicolumn{5}{|l|}{ Laboratory data } \\
\hline HbAlc (\%) & $6.1 \pm 1.0$ & $6.2 \pm 1.1$ & $6.1 \pm 1.0$ & 0.882 \\
\hline Serum Alb $(g / d L)$ & $4.4 \pm 0.4$ & $4.4[4.1-4.6]$ & $4.4 \pm 0.5$ & 0.495 \\
\hline Serum Cr (mg/dL) & $1.28[1.12-1.58]$ & $1.57[1.41-1.76]$ & $1.09 \pm 0.13$ & - \\
\hline Serum uric acid $(\mathrm{mg} / \mathrm{dL})$ & $5.4 \pm 1.3$ & $5.7 \pm 1.5$ & $5.2 \pm 1.0$ & 0.304 \\
\hline Serum potassium $(\mathrm{mmol} / \mathrm{L})$ & $4.8 \pm 0.5$ & $4.8[4.6-5.1]$ & $4.7 \pm 0.5$ & 0.335 \\
\hline Serum phosphorus (mg/dL) & $2.2 \pm 0.5$ & $2.3 \pm 0.3$ & $2.2 \pm 0.6$ & 0.377 \\
\hline Triglyceride (mg/dL) & $116[94-165]$ & $128[107-165]$ & $102[82-169]$ & 0.200 \\
\hline HDL cholesterol (mg/dL) & $59 \pm 12$ & $58 \pm 12$ & $59 \pm 13$ & 0.758 \\
\hline LDL cholesterol (mg/dL) & $117 \pm 29$ & $117 \pm 29$ & $116 \pm 31$ & 0.930 \\
\hline \multicolumn{5}{|l|}{ Medication } \\
\hline Mycophenolatemofetil & $32(100)$ & $16(100)$ & $16(100)$ & - \\
\hline Tacrolimus & $32(100)$ & $16(100)$ & $16(100)$ & - \\
\hline Cyclosporine & $0(0)$ & $0(0)$ & $0(0)$ & - \\
\hline Everolimus & $0(0)$ & $0(0)$ & $0(0)$ & - \\
\hline Steroid & $32(100)$ & $16(100)$ & $16(100)$ & - \\
\hline Antihypertensive agent & $17(53)$ & $8(50)$ & $9(56)$ & 0.723 \\
\hline Diabetes agent & $11(34)$ & $6(38)$ & $5(31)$ & 0.710 \\
\hline Dyslipidemia agent & $0(0)$ & $0(0)$ & $0(0)$ & - \\
\hline Hyperuricemia agent & $1(3)$ & $1(6)$ & $0(0)$ & 0.500 \\
\hline
\end{tabular}

Values are expressed as the mean \pm standard deviation, median [interquartile range] or the number of patients (percentage). Independent $t$-test, Mann-Whitney test, chi-squared test, Fisher's exact test.

\section{Discussion}

One of the most important findings of the present study was that serum $\mathrm{Cr}$ concentrations at one month after transplantation were closely related to those at 12 months.

In renal transplantation from a living donor, the serum $\mathrm{Cr}$ concentrations are restored to normal levels immediately after reperfusion of the transplanted kidney. Recipients usually withdraw from dialysis treatment unless serious acute rejection of the renal graft occurs. In cases involving deceased donor renal transplantation or in a prolonged ischemic time, the renal function rapidly deteriorates [15]. We compared the differences in background characteristics before 
Table 5. The physical findings, renal function and laboratory data at 1 month after transplantation in female patients.

\begin{tabular}{|c|c|c|c|c|}
\hline & Total $(\mathrm{n}=20)$ & $\begin{array}{c}\text { Group H } \\
(\mathrm{n}=10)\end{array}$ & $\begin{array}{l}\text { Group L } \\
(\mathrm{n}=10)\end{array}$ & $\begin{array}{l}\mathrm{p} \text { value } \\
\text { ( } \mathrm{H} \text { vs } \mathrm{L} \text { ) }\end{array}$ \\
\hline \multicolumn{5}{|l|}{ Physical findings } \\
\hline $\mathrm{SBP}(\mathrm{mmHg})$ & $138 \pm 15$ & $142 \pm 16$ & $134 \pm 14$ & 0.267 \\
\hline $\mathrm{DBP}(\mathrm{mmHg})$ & $90 \pm 12$ & $90 \pm 13$ & $90 \pm 13$ & 0.931 \\
\hline BMI $\left(\mathrm{kg} / \mathrm{m}^{2}\right)$ & $20.8[16.9-27.4]$ & $25.7 \pm 5.6$ & $18.7 \pm 3.0$ & 0.004 \\
\hline \multicolumn{5}{|l|}{ Laboratory data } \\
\hline HbAlc (\%) & $5.6[5.4-6.2]$ & $5.9 \pm 0.8$ & $5.6[5.3-6.4]$ & 0.859 \\
\hline Serum Alb (g/dL) & $4.2 \pm 0.4$ & $4.1 \pm 0.4$ & $4.3 \pm 0.4$ & 0.148 \\
\hline Serum Cr $(\mathrm{mg} / \mathrm{dL})$ & $0.81[0.73-1.05]$ & $1.10 \pm 0.27$ & $0.71 \pm 0.05$ & - \\
\hline Serum uric acid $(\mathrm{mg} / \mathrm{dL})$ & $4.8[3.8-5.7]$ & $5.5 \pm 1.1$ & $4.2[3.1-4.8]$ & 0.026 \\
\hline Serum potassium $(\mathrm{mmol} / \mathrm{L})$ & $4.3 \pm 0.5$ & $4.4 \pm 0.6$ & $4.3 \pm 0.4$ & 0.629 \\
\hline Serum phosphorus (mg/dL) & $2.4 \pm 0.8$ & $1.8[1.6-2.4]$ & $2.7 \pm 0.8$ & 0.173 \\
\hline Triglyceride (mg/dL) & $105[78-146]$ & $113[85-142]$ & $95[75-161]$ & 0.705 \\
\hline HDL cholesterol (mg/dL) & $80 \pm 27$ & $73 \pm 24$ & $89 \pm 29$ & 0.261 \\
\hline LDL cholesterol (mg/dL) & $113[87-169]$ & $134 \pm 43$ & $111 \pm 30$ & 0.183 \\
\hline \multicolumn{5}{|l|}{ Medication } \\
\hline Mycophenolatemofetil & $20(100)$ & $10(100)$ & $10(100)$ & - \\
\hline Tacrolimus & $19(95)$ & $10(100)$ & $9(90)$ & 0.500 \\
\hline Cyclosporine & $1(5)$ & $0(0)$ & $1(10)$ & 0.500 \\
\hline Everolimus & $0(0)$ & $0(0)$ & $0(0)$ & - \\
\hline Steroid & $19(95)$ & $10(100)$ & $9(90)$ & 0.500 \\
\hline Antihypertensive agent & $10(50)$ & $5(50)$ & $5(50)$ & 1.000 \\
\hline Diabetes agent & $3(15)$ & $2(20)$ & $1(10)$ & 0.500 \\
\hline Dyslipidemia agent & $0(0)$ & $0(0)$ & $0(0)$ & - \\
\hline Hyperuricemia agent & $0(0)$ & $0(0)$ & $0(0)$ & - \\
\hline
\end{tabular}

Values are expressed as the mean \pm standard deviation, median [interquartile range] or the number of patients (percentage). Independent $t$-test, Mann-Whitney test, chi-squared test, Fisher's exact test.

transplantation and in the clinical and nutritional data throughout the follow-up period between Group H and Group L.

Using a stepwise multiple regression analysis we demonstrated that the salt intake of male recipients was an independent predictor of the renal function at 12 months. The salt intake before and immediately after transplantation was not available in the present study. Thus, we could not definitely address the appropriate salt intake after kidney transplantation. However, considering that the average salt intake at 3 months after transplantation was $9.9 \mathrm{~g} /$ day in Group L and $12.1 \mathrm{~g} /$ day in Group $\mathrm{H}$, it is conceivable that the salt intake should be kept to < $10 \mathrm{~g} /$ day after transplantation. 


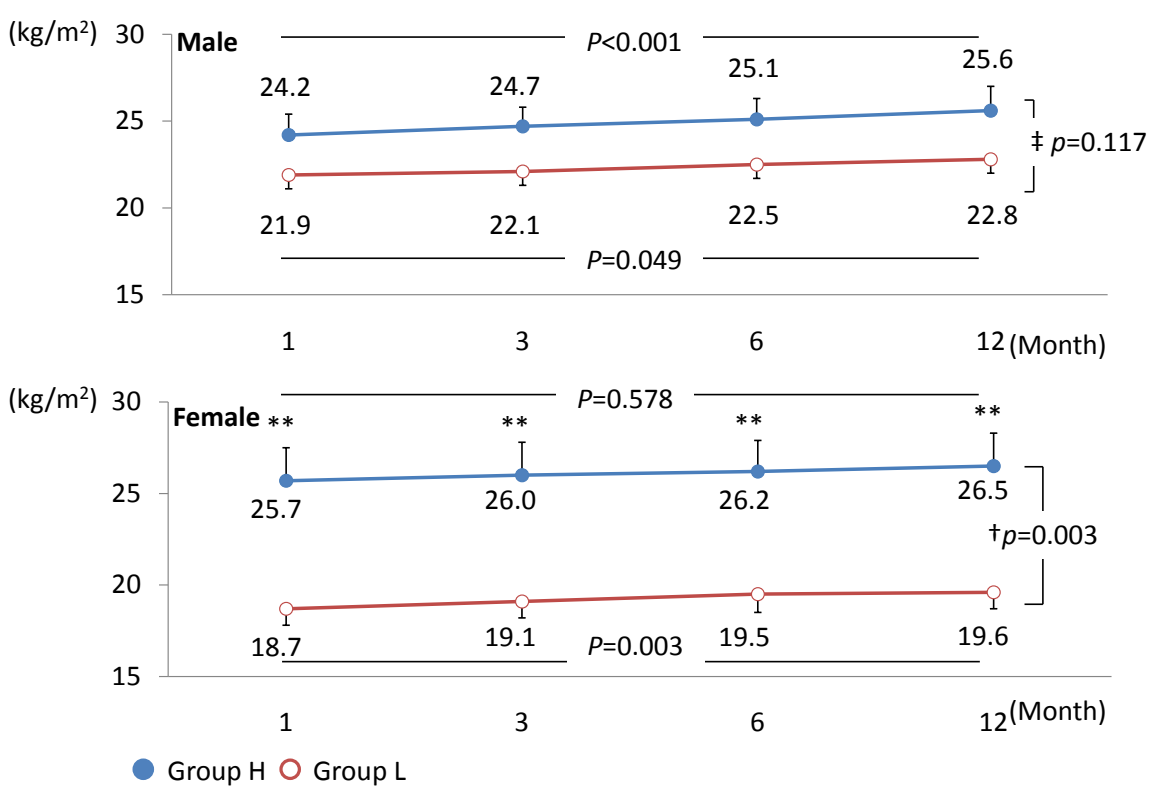

Figure 6. The clinical course of the BMI values during the study period. The values are expressed as mean \pm SD. The open circles represent the values in Group L. The closed circles represent the values in Group H. The vertical axis represents the BMI, while the horizontal axis represents the period of the study. The upper graph shows male recipients, while the lower graph shows female recipients. The differences in each group of male recipients during the whole study period were analyzed by the Friedman test or a repeated measures ANOVA ( $p<0.001$ for Group H and $p=0.049$ for Group L). The differences in each group of female recipients during the whole study period were analyzed by a repeated measures ANOVA ( $p=0.587$ for Group $\mathrm{H}$ and $p=0.003$ for Group L). The differences between Groups L and $\mathrm{H}$ during the whole study period were analyzed by a mixed-effects model ( $\ddagger)$ or a two-way repeated measures ANOVA $(\dagger)(p=0.117$ for male recipients and $p=0.003$ for female recipients).

In this context, Cianciaruso et al. reported that patients with chronic kidney disease (CKD) who were on a low-sodium diet at baseline achieved better renal outcomes during a 3 years of follow-in comparison to those with a high-sodium diet, while there were no differences in the mean blood pressure values of the two groups [16]. Considering these data, salt restriction in CKD patients improves the outcomes of renal disease, independent of any antihypertensive effects. Nevertheless, a future study should be performed to clarify how the salt intake influences the renal graft function.

In contrast, in the overall female recipient population, there was a significant positive correlation between the serum $\mathrm{Cr}$ concentration and the serum uric acid concentration and BMI at 12 months after transplantation. A stepwise multiple regression analysis demonstrated that BMI was independently associated with the renal function 12 months after transplantation. Moreover, the BMI values of the patients in Group $\mathrm{H}$ were higher than the values of the patients in Group L throughout the follow-up. In a retrospective study of 51,927 recipients, Meier-Kriesche et al. demonstrated that BMI markedly influences graft survival after renal transplantation [17]. Recipients with a BMI of $>36 \mathrm{~kg} / \mathrm{m}^{2}$ exhibited 


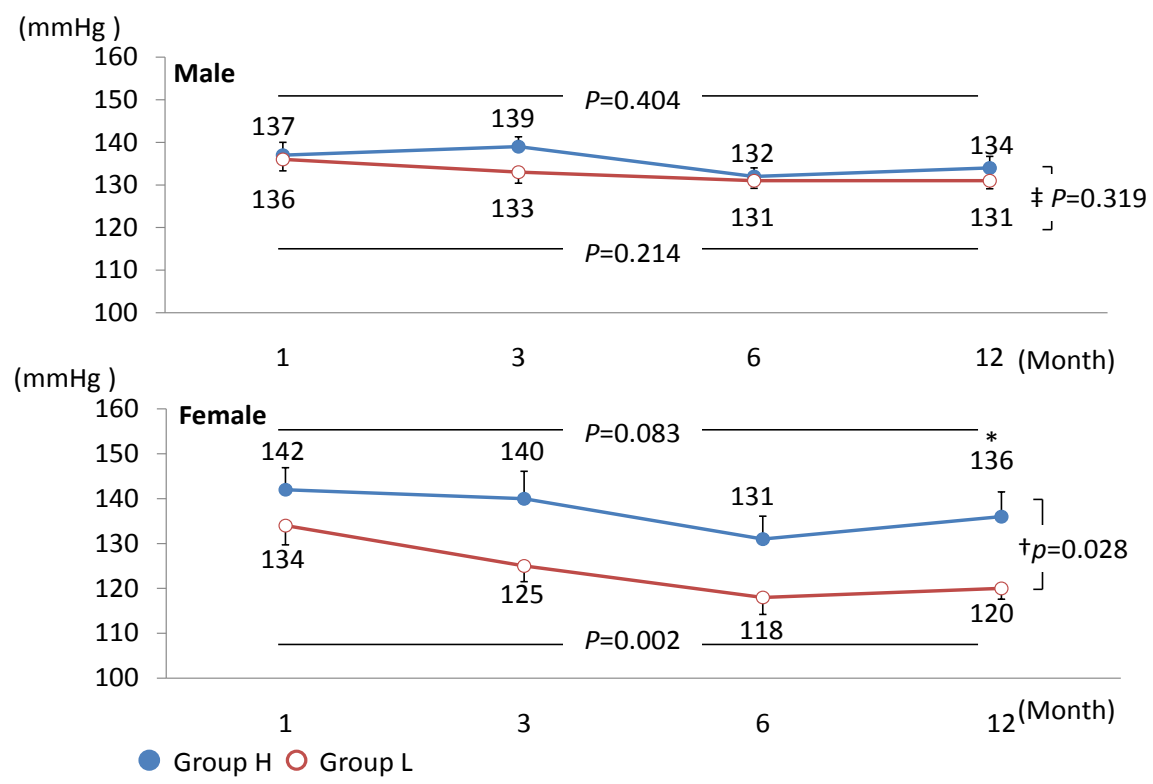

Figure 7. The clinical course of the SBP values during the study period. The values are expressed as mean \pm SD. The open circles represent the values in Group L. The closed circles represent the values in Group $\mathrm{H}$. The vertical axis represents the SBP values, while the horizontal axis represents the period of the study. The upper graph shows male recipients, while the lower graph shows female recipients. The differences in each group of male recipients during the whole study period were analyzed by the Friedman test or a repeated measures ANOVA ( $p=0.404$ for Group H and $p=0.214$ for Group L). The differences in each group of female recipients during the whole study period were analyzed by a repeated measures ANOVA ( $p=0.083$ for Group H and $p=0.002$ for Group L). The differences between Groups $\mathrm{L}$ and $\mathrm{H}$ during the whole study period were analyzed by a mixed-effects model $(\ddagger)$ or a two-way repeated measures ANOVA $(\dagger)(p=0.319$ for male recipients and $p=0.028$ for female recipients).

markedly worse graft survival and had a higher rate of CVD-related mortality. A meta-analysis of obese and non-obese patients who underwent kidney transplantation demonstrated that obesity was associated with a delayed graft function, and increased CVD-related mortality in recipients [18]. Taken together, it is suggested that body weight control is very important for maintaining the renal function after kidney transplantation. Our results supported these previous studies, and suggest that the BMI should be $<20 \mathrm{~kg} / \mathrm{m}^{2}$, particularly in female recipients.

In the male recipients, there were no differences in the background characteristics of those in Groups $\mathrm{H}$ and $\mathrm{L}$, whereas in the female recipients the BMI values of the recipients in Group $\mathrm{H}$ were significantly higher than those of the recipients in Group L. This might suggest that obesity in ESRD influences the serum $\mathrm{Cr}$ concentrations at one month after transplantation.

The present study is associated with some limitations, including the small sample size and the fact that it was performed in a single center. A multicenter collaborative study with a larger study population is needed in order to make any conclusions with regard to the dietary intake standards to maintain the kidney function of Japanese patients after transplantation. 


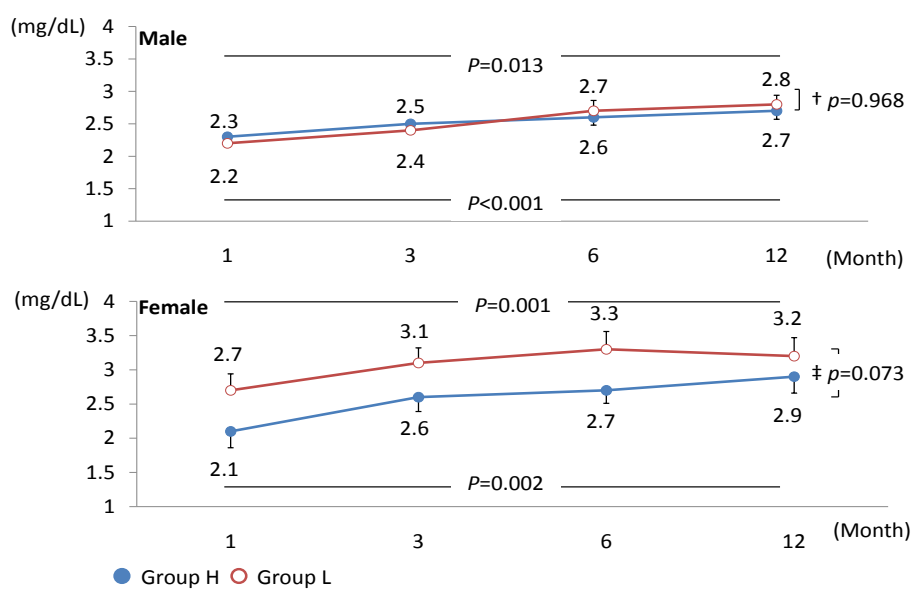

Figure 8. The clinical course of the serum phosphorus levels during the study period. The values are expressed as mean $\pm \mathrm{SD}$. The open circles represent the values in Group L. The closed circles represent the values in Group $H$. The vertical axis represents the serum phosphorus levels, while the horizontal axis represents the period of the study. The upper graph shows male recipients, while the lower graph shows female recipients. The differences in each group of male recipients during the whole study period were analyzed by a repeated measures ANOVA ( $p=0.013$ for Group H and $p<0.001$ for Group L). The differences in each group of female recipients during the whole study period were analyzed by the Friedman test or a repeated measures ANOVA ( $p=0.002$ for Group $\mathrm{H}$ and $p=0.001$ for Group L). The differences between Groups L and $\mathrm{H}$ during the whole study period were analyzed by a two-way repeated measures ANOVA $(\dagger)$ or a mixed-effects model $(\ddagger)$ ( $p=$ 0.968 for male recipients and $p=0.073$ for female recipients).

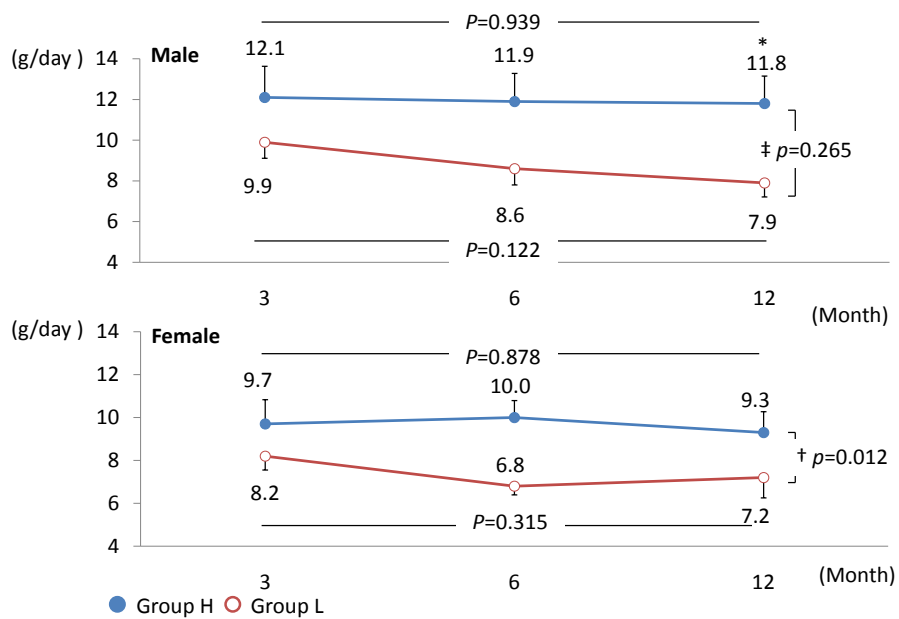

Figure 9. The clinical course of the salt intake during the study period. The values are expressed as mean \pm SD. The open circles represent the values in Group L. The closed circles represent the values in Group $\mathrm{H}$. The vertical axis represents the salt intake, while the horizontal axis represents the period of the study. The upper graph shows male recipients, while the lower graph shows female recipients. The differences in each group of male recipients during the whole study period were analyzed by the Friedman test or a repeated measures ANOVA ( $p=0.939$ for Group H and $p=0.122$ for Group L). The differences in each group of female recipients during the whole study period were analyzed by a repeated measures ANOVA ( $p=0.878$ for Group $\mathrm{H}$ and $p=0.315$ for Group L). The differences between Groups $\mathrm{L}$ and $\mathrm{H}$ during the whole study period were analyzed by amixed-effects model ( $\ddagger)$ or a two-way repeated measure ANOVA $(\dagger)(p=0.265$ for male recipients and $p$ $=0.012$ for female recipients). 


\section{Conclusion}

In conclusion, recipients exhibited a low or normal kidney function, as measured by the serum $\mathrm{Cr}$ concentration, at one month after renal transplantation. This remained throughout the one-year follow-up period. The daily salt intake was independently associated with the serum $\mathrm{Cr}$ concentration during the one-year follow-up period in male recipients. On the other hand, in female recipients, the BMI was independently associated with the serum Cr concentration during the one-year follow-up period. Blood pressure did not affect the serum $\mathrm{Cr}$ concentrations. It is necessary to consider sex differences when investigating factors contributing to the renal function after kidney transplantation.

\section{Acknowledgements}

This study was supported in part by grants from SHISEIKAI Scientific Award (2016) and Ohyukai Kyoritsu Women's University (2017). We gratefully acknowledge the excellent support of the stuff of division of Renal Surgery and Transplantation, Department of Urology, Jichi Medical University.

\section{Compliance with Ethical Standards}

All procedures performed in analysis involving human participants were in accordance with the ethical standards of the institutional and/or national research committee at which the studies were conducted (the ethics committee approval number 15-067: the Jichi Medical University) and with the 1964 Helsinki declaration and its later amendments or comparable ethical standards. The authors have declared that no conflict of interest exists. Concerning informed consent, we provided the patients with the opportunity to opt out by displaying an outline of the analysis.

\section{Conflicts of Interest}

The authors declare no conflicts of interest regarding the publication of this paper.

\section{References}

[1] The Japanese Society for Transplantation (2017) Fact Book 2016 of Organ Transplantation in Japan. http://www.asas.or.jp/jst/pdf/factbook/factbook2016.pdf

[2] Nishi, S., Gejyo, F., Saito, K. and Takahashi, K. (2004) Kidney Transplantation and Life-Style Related Diseases. Nihon JinzoGakkai Shi, 46, 792-797. (In Japanese)

[3] Midtvedt, K. and Neumayer, H.H. (2000) Management Strategies for Posttransplant Hypertension. Transplantation, 70, SS64-SS69.

[4] Tedla, F., Hayashi, R., McFarlane, S.I. and Salifu, M.O. (2007) Hypertension after Renal Transplant. Journal of Clinical Hypertension (Greenwich), 9, 538-545. https://doi.org/10.1111/j.1524-6175.2007.06588.x

[5] Bellinghieri, G., Bernardi, A., Piva, M., Pati, T., Stoppa, F., Scaramuzzo, P., Garizzo, O., Santoro, D., Savica, V. and Bucciante, G. (2009) Metabolic Syndrome after Kid- 
ney Transplantation. Journal of Renal Nutrition, 19, 105-110.

https://doi.org/10.1053/j.jrn.2008.10.002

[6] Tutone, V.K., Mark, P.B., Stewart, G.A., Tan, C.C., Rodger, R.S., Geddes, C.C. and Jardine, A.G. (2005) Hypertension, Antihypertensive Agents and Outcomes Following Renal Transplantation. Clinical Transplantation, 19, 181-192.

https://doi.org/10.1111/j.1399-0012.2004.00315.x

[7] Porrini, E., Delgado, P., Bigo, C., Alvarez, A., Cobo, M., Checa, M.D., Hortal, L., Fernández, A., García, J.J., Velázquez, S., Hernández, D., Salido, E. and Torres, A. (2006) Impact of Metabolic Syndrome on Graft Function and Survival after Cadaveric Renal Transplantation. American Journal of Kidney Disease, 48, 134-142. https://doi.org/10.1053/j.ajkd.2006.04.078

[8] Tamura, K., Okubo, M., Osakabe, T., Sato, K. amd Endo, T. (1992) Clinical Prognostics Studied in 30 Leng-term Suryivors of Syngenesioplastic Renal Transplantation. Kitasato Med, 22, 93-104.

[9] Toigo, G., Aparicio, M., Attman, P.O., Cano, N., Cianciaruso, B., Engel, B., Fouque, D., Heidland, A., Teplan, V. and Wanner, C. (2000) Expert Working Group Report on Nutrition in Adult Patients with Renal Insufficiency (Part 2 of 2). Clinical Nutrition, 19, 281-291. https://doi.org/10.1054/clnu.2000.0129

[10] Chan, M., Patwardhan, A., Ryan, C., Trevillian, P., Chadban, S., Westgarth, F. and Fry, K. (2011) Evidence-Based Guidelines for the Nutritional Management of Adult Kidney Transplant Recipients. Journal of Renal Nutrition, 21, 47-51. https://doi.org/10.1053/j.jrn.2010.10.021

[11] Japanese Society for Clinical Renal Transplantation (2011) The Clinical Guideline for Medical and Pediatric Complications after Kidney Transplantation. NIHON IGAKUKAN, Tokyo.

[12] Japanese Society of Nephrology (2014) Dietary Recommendations for Chronic Kidney Disease 2014. Nihon JinzoGakkai Shi, 56, 553-599. (In Japanese)

[13] Maroni, B.J., Steinman, T.I. and Mitch, W.E. (1985) A Method for Estimating Nitrogen Intake of Patients with Chronic Renal Failure. Kidney International, 27, 58-65. https://doi.org/10.1038/ki.1985.10

[14] Shimamoto, K., Ando, K., Fujita, T., Hasebe, N., Higaki, J., Horiuchi, M., Imai, Y., Imaizumi, T., Ishimitsu, T., Ito, M., Ito, S., Itoh, H., Iwao, H., Kai, H., Kario, K., Kashihara, N., Kawano, Y., Kim-Mitsuyama, S., Kimura, G., Kohara, K., Komuro, I., Kumagai, H., Matsuura, H., Miura, K., Morishita, R., Naruse, M., Node, K., Ohya, Y., Rakugi, H., Saito, I., Saitoh, S., Shimada, K., Shimosawa, T., Suzuki, H., Tamura, K., Tanahashi, N., Tsuchihashi, T., Uchiyama, M., Ueda, S. and Umemura, S. (2014) The Japanese Society of Hypertension Guidelines for the Management of Hypertension (JSH 2014). Hypertension Research, 37, 253-390.

https://doi.org/10.1038/hr.2014.20

[15] Ojo, A.O., Wolfe, R.A., Held, P.J., Port, F.K. and Schmouder, R.L. (1997) Delayed Graft Function: Risk Factors and Implications for Renal Allograft Survival. Transplantation, 63, 968-974. https://doi.org/10.1097/00007890-199704150-00011

[16] Cianciaruso, B., Bellizzi, V., Minutolo, R., Tavera, A., Capuano, A., Conte, G. and De Nicola, L. (1998) Salt Intake and Renal Outcome in Patients with Progressive Renal Disease. Mineral and Electrolyte Metabolism, 24, 296-301. https://doi.org/10.1159/000057385

[17] Meier-Kriesche, H.U., Arndorfer, J.A. and Kaplan, B. (2002) The Impact of Body Mass Index on Renal Transplant Outcomes: A Significant Independent Risk Factor 
for Graft Failure and Patient Death. Transplantation, 73, 70-74.

https://doi.org/10.1097/00007890-200201150-00013

[18] Nicoletto, B.B., Fonseca, N.K., Manfro, R.C., Gonçalves, L.F., Leitão, C.B. and Souza, G.C. (2014) Effects of Obesity on Kidney Transplantation Outcomes: A Systematic Review and Meta-Analysis. Transplantation, 98, 167-176.

https://doi.org/10.1097/TP.0000000000000028 